\title{
Simulation for Collaborative Serious Game Using Player's Modeling and Agent Technology
}

\author{
Hadya Boufera ${ }^{1}$ and Fatima Bendella ${ }^{2}$
}

\begin{abstract}
The concept of multiplayer serious games that support collaborative learning offers advantages and opportunities. It can add a social part to the process of gaming, stressing the role of interaction between players, affecting social skills like teamwork or communication and competence skills.

Players have different preferences and styles of gaming. Current approaches to adapt game make it possible for different elements to adjust to the player. However most of these approaches can adapt one single player; so we need to find ways to aggregate all users input and history into some potential information that can be used for the adaptation mechanism. Based on player's modeling and agent technology, A model to simulate collaborative multiplayer serious games has proposed in this paper.
\end{abstract}

Keywords - player's modelling, agent technology, collaborative learning, serious game.

\section{INTRODUCTION}

Game-Based Learning (GBL) is used as a learning strategy through game play. Various researches [1] have shown that Collaborative serious game enhances social competencies such as collaborative decision-making, negotiation and communication. The essence of serious game is to be adapted according to the level skill of each user. This user is defined and coded in the game: all serious game include a profile of the user. In one single player games, it presents a classification of the target players and a memory of player's actions in the game. In multiplayer games the model contains social parameters and behaviors, and it can also be a cognitive model.

With Serious game technology and Collaborative learning, users-centred design is required now more than ever to provide an adaptable and personal content (level); Due to the lack of concepts for multiplayer serious games, only a limited number of Serious Games have been designed with multiplayer support. Multiplayer Serious Game used with collaborative learning purposes should be adaptable to each player; so we need to find ways to aggregate all users input and history into some potential information that can be used

for the adaptation mechanism. We believe that user's profiling respond to these need by providing a detail analysis of player's performance.

We aim to provide an approach for game adaptation

${ }^{1}$ Computer Science Department, University of Mascara, Mascara, ALGERIA

${ }^{2}$ Computer Science Department, University of USTO, Oran, ALGERIA correlated to a user's profile. It will supply response to each player's individual needs. The goal of our research is to define a profile of users able to define the strategy of adaptation to all players and support the collaborative learning principals in multiplayer serious game.

In this paper we give a brief survey of the current researches on user's profile for game adaptation next we introduce a possible structure of user's profile and. In the end, the conclusion and future work are given

\section{RELATED WORKS}

In literature, different definitions of the term Serious Games can be found: serious game is a game that their primary purpose is not entertainment or enjoyment but it usually refer to the game used for training, education. This implies that all serious games designed like games, its use technology game: game play, rules, goals and these elements are fused with domain relevant method, technologies and concepts, e.g. pedagogic concepts for educational games.

Serious games technologies are use for diverse purposes, such as simulation environments for emergency (medical, fire commander, police). Serious Games concepts are applied in an educational context to support learners at school or university, or in a health context to motivate people for sports, or other health aspects of life. Other examples of Serious Games centre on culture, public awareness of societal issues e.g., religion, politics.

\section{A. Player modeling}

Player modeling is the most studied area in current Technology Enhanced Learning systems dedicated for games, which is a necessary feature to meet the effectiveness requirement for each adaptive game. Several research areas on model have conducted, there are two distinct ways of implementing player model: player-controlled and computercontrolled [3], the first one tries to adapt game according to a feedback given by the player/user, the second personalize game according to player's needs and preferences.

Picard [4] has based on emotional communication (frustration, confusion, disliking, interest...) to design player model. Smith et al. $[4,5]$ introduce a classification of player modeling. They define a player model using the four dimensions scope of application, purpose of use, domain of modeled details, and source of model's derivation or motivation.

According to Bartle [6], in role-playing, players that have same preference can be grouped into same category: achiever, 
explorer, socializer and killer. These types are generated from the analysis of a multi-user dungeon (MUDs). The player's model proposed in [7] considered three possible levels: "user modeling, which includes a profile of an individual player/user, user clustering, which is based on similarities between user profiles and forming a user cluster using some form of automated technique, and community modeling, which includes a model about the social group as a whole, not as the sum or the average of its individual member's profiles". These levels can be used simultaneously to personalize social and individual preference in multiplayer serious game. Many applications in internet training system [12] have used an user model based on three levels: generic model which includes general information about the player (age, gender...), in addition to general information, localized model represents knowledge of the user's location and personalized model is based on complex state variables about each user. [8] proposed a player's model called group model, it based on communication and action between players. User's model proposed by most these works still utilizable in specific domain and not generalized. All of these methods use the user's profile to optimize the playability factor of the game and few works have exploited the adaption in game according to the player's profile.

\section{B. Multiplayer game in collaborative learning}

The use of serious games with group activities in which the primary activity for the trainee is the action of playing, the knowledge and cognitive skills development are the result of this process. Our main research goal is based on the collaborative learning which offers group trainees to achieve common goals while they are learning. Collaborative learning fosters development of interpersonal competencies and social connectivism such as collaborative decision making, negotiation and creative solution. In multiplayer serious games each trainee depend on others, they help and provide advises to others.

Roschelle and Teasley [9] define collaboration as "a coordinated, synchronous activity that is the result of a continued attempt to construct and maintain a shared conception of a problem". Dillenbourg defines collaboration as follows: "In collaboration, partners do the work 'together'." [10] Thomson et al. state the following about collaboration: "Collaboration is a multidimensional, variable construct composed of five key dimensions, two of which are structural in nature (governance and administration), two of which are social capital dimensions (mutuality and norms), and one of which involves agency (organizational autonomy)." (Thomson et al. [11]).

The various definitions of collaboration are used as a basis for a formalization of the concept of collaborative learning, which is used widely in game-based learning. There are several parameters defining the success of collaborative learning. One Most important factor is the group of learners. The group is characterized by its size, and by its composition. Level of competence and preferences should be taken into account when forming groups. In addition to that, Johnson and Johnson (1994) propose five essential components which enhance collaborative work [11:
- Positive interdependence: A group success or failure represents individual success or failure, each player cannot succeed alone.

- Individual accountability: The results of each individual performance evaluation are given back to both the group and the individual.

- Face to face promotive interaction: Promoting behavior, each trainee encourages others to success by helping, sharing their knowledge during learning process.

- Social skills: Group skills, interpersonal competencies and communication are essential to enhance the collaborative work.

- Group processing: The group evaluates itself to estimate their work.

\section{STRUCTURE OF PLAYER'S MODEL}

In order to simulate a collaborative serious game towards players with various characteristics like player skill's level, and, play and learning style, communication and teamwork. The player model should have all features in term of learning, gaming and interaction and the group model is the combine of player/learner and interaction model of all players. In our context, we are based on these guidelines (see Johnson and Johnson 1994) to propose the conceptual user's profile.

The user's profile is based on two levels: learner/player model, group model.

\section{A. Learner model}

Which collects data about the player, it includes possible estimation of the skill levels and competence of the player, this information can be obtained through deliberate answer investigation or induced in real time from actions and behavior of the player. The proposed player model (table 1) is composed of three categories: personal, goal and task. Personal attributes contains general information about the trainee and his/her score (competences), the next categories are related to trainee achievements and contains information about goals and tasks that a trainee must address, has started or has achieved. The attributes related to these categories are initially empty, and they are updated when the trainee is playing. The list of goals must be specified before starting game because they must have a common goal for all group members. When a faced goals accomplished (proportion of tasks completed), then the achieved goals list is updated because all tasks associated with this goal have been completed. The attributes related to tasks work similarly to those just explained. Attributes (Best task and worst task) are intended to adapt the game to avoid the difficulties. In this way, the system has more information to propose the trainee who can help others. 


\begin{tabular}{|c|c|}
\hline Attribute & description \\
\hline Identifier & Identification \\
\hline Name & Trainee name \\
\hline Age & Trainee current age \\
\hline Sex & Trainee gender \\
\hline Score (skill level) & Marks obtained \\
\hline Proposed goals & List of proposed goals to be leaming \\
\hline Faced goals & List of goals that the trainee has started, tasks completed. \\
\hline Achieved goals & List of goals that the trainee has achieved \\
\hline Proposed tasks & List of proposed tasks to be performed \\
\hline Faced tasks & List of tasks that the trainee has started, \\
\hline Achieved tasks & List of tasks that the trainee has achieved \\
\hline Best task & $\begin{array}{l}\text { Ordered list of tasks which this trainee obtains the best } \\
\text { results }\end{array}$ \\
\hline Worst task & $\begin{array}{l}\text { Ordered list of tasks which this trainee obtains the worst } \\
\text { results }\end{array}$ \\
\hline
\end{tabular}

\section{B. Group Model}

The goal of the social model is to deduce preferences and level of each player from social interaction, it allow changing player's level. The Social model must be able to gather social skills and generate feedback related to the interaction between players. The group model is also composed of three categories: tasks (game play), interaction and evaluation. The first contains the number of trainees needed to solve the proposed task, and if more than one, it describes how trainees must address the task (type task). The attribute difficulty task is related to general difficulty of this task. The second category contains information about the general features of the group, three attributes are included: Most connected trainee, most influential trainee, and interaction network. The last category defines task levels and describes the rules (formulae) to calculate the general score.

TABLE II: GROUP MODEL

\begin{tabular}{ll}
\hline \hline Attribute & Description \\
\hline $\begin{array}{l}\text { Trainees } \\
\text { Type task }\end{array}$ & $\begin{array}{l}\text { Number of trainees that must participate in this task } \\
\text { When this task is for a group, defines the way } \\
\text { in which the trainees must address it }\end{array}$ \\
$\begin{array}{l}\text { Difficulty task } \\
\text { Most connected trainee }\end{array}$ & $\begin{array}{l}\text { Gifficulty of task } \\
\text { Most influential trainee }\end{array}$ \\
$\begin{array}{l}\text { Communication } \\
\text { Getwork }\end{array}$ & Number of contacts made by group \\
Levels & Describe task level and rules to calculate score \\
General score & Score for all group member \\
\hline \hline
\end{tabular}

\section{Collaborative Multiplayer Serious Game SIMULATION CONCEPT}

The collaborative serious game simulation developed in this work take in the count to simulate realistic behavior of players/learners. The proposed approach is to simulate real players playing the game.

Simulation is based on agent technology; the players agents then achieve the goals based on their player/learner, and interaction model, select the most suitable plan for the goal and execute it. The evaluation of behavior is done by comparing the resulting behavior with the required behavior.

\section{A. Agent Based Player}

Collaborative multiplayer serious game can be considered like high dynamic organization, player goals might constantly changes. The player agent architecture consists of three modules: perception module, planning/decision module and control module. The perception module is responsible for processing the information gathered from the game and for updating the state of the world; the planning module evaluates the player model and current information about the game world in order to decide which plan should be executed and the control module decides which game actions the simulated player should execute based on the current plan and player model.

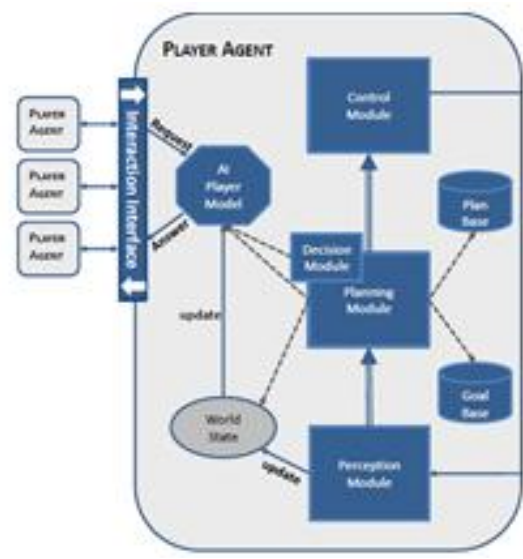

Fig. 1: architecture of player agent.

To validate our approach, we simulate a scenario, the propose of the game is to train firecommander on how to work together with all team under pressure to extinguish fire and evacuate victim. We have players (learners) in the role of a firecommander. One important element in fire commander training is the behavior of the fire. So we are modeled the fire as an agent.

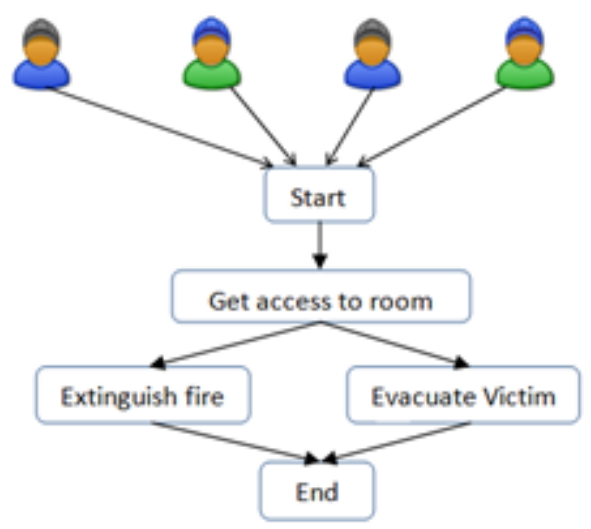

Fig. 2: scenario example

The blocks in the figure 2 represent subscenes. In this game, agents simulate firemen with their own preferences, skills and own memory of past games. The first evaluation on performance is done when the trainee has finished extinguishing one room or when another ending criteria is reached. When this period is over we get feedback about the performance of the learner. We assume that the trainee has to learn three skill categories: Extinguishing fire, giving orders to the team, and rescue victims. 


\section{RESULTS AND DISCUSSIONS}

To decide if the approach based on collaborative learning proposed, promoted learning. We need to compare directly with the same approach without taken in a count the concept of collaborative learning in player model.

The comparison is done according to various criteria like number of messages between players (interaction), accomplishment of goal (success/failure).

The impact of the number of success implies that the simulated players learn perfectly when they playing/learning in collaborative see figure 4 .

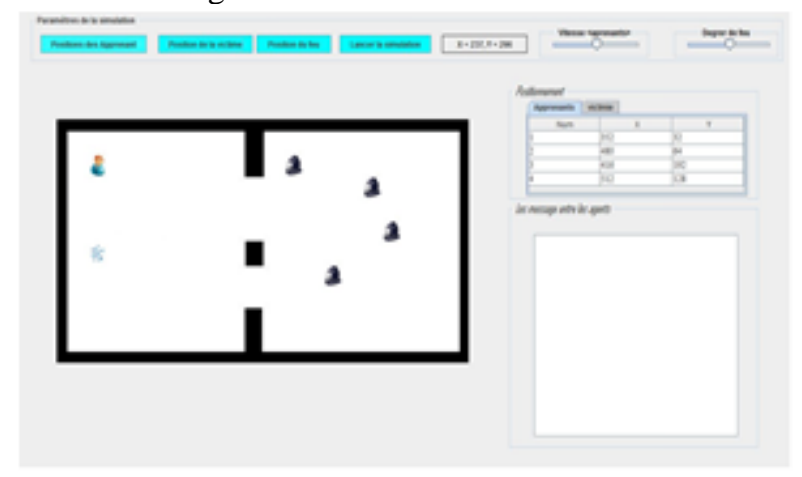

Fig. 3:Example of simulation

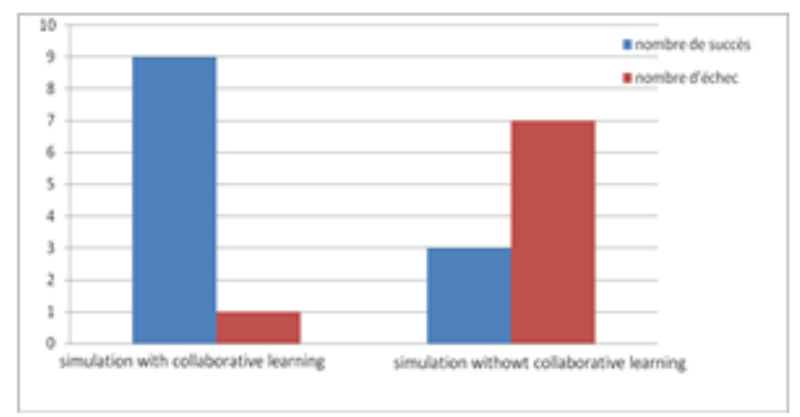

Fig. 4: Results of simulation

\section{CONCLUSION AND FUTURE WORKS}

Collaborative learning an important research area in multiplayer serious games, however only a limited number of games have been designed according to the collaborative learning rules.

This paper has proposed a model to analyze and simulate collaborative learning in serious games. The simulation is based on multi agent system, a player model has been presented, it contains information about what trainees have learned, how they have collaborated and the difficulties encountered. We are in the process to define a platform to integrate this model with a set of others models to aggregate all users input and history into some potential information to carry out an adaptive multiplayer serious game. In this manner, it is possible to adjust the difficulty to each trainee.

\section{REFERENCES}

[1] M. Romero, M. Usart, M. Ott, J. Earp, “ Learning Through Playing For Or Against Each Other? “, Promoting Collaborative Learning In Digital Game Based Learning, ECIS 2012 Proceedings, pp 93.
[2] S. Natkin, C. Yan, "User Model in Multiplayer Mixed Reality", ACE'06, ACM SIGCHI int. conf. on Advances in computer entertainment technology, Vol. 266, pp.74-82, 2006.

[3] P. Spronck, M.Ponsen, I. Sprinkhuizen-Kuype, E. Postma, "Adaptive game AI with dynamic scripting. In journal Machine learning”, (2006), Vol.63, No.3, pp. $217-248$. http://dx.doi.org/10.1007/s10994-006-6205-6

[4] Adam M. Smith, Chris Lewis, Kenneth Hullet, and Anne Sullivan. An Inclusive View of Player Modeling. In Proceedings of the 6th International Conference on Foundations of Digital Games, pages 301303. ACM, 2011.

[5] Adam M. Smith, Chris Lewis, Kenneth Hullett, Gillian Smith, and Anne Sullivan. An Inclusive Taxonomy of Player Modeling. Technical Report UCSC-SOE- 11-13, University of California, Santa Cruz, 2011.

[6] R. W. Picard, "Affective Computing for HCI". In Proceedings HCI, Munich, (1999) Germany.

[7] R. A. Bartle, "Hearts, Clubs, Diamonds, Spades: Players Who Suit MUDs". (1996) Retrieved May 2, 2013, from http://mud.co.uk/richard/hcds.htm.

[8] M. Turpeinen, T. Saari, "System Architecture for Psychological Customization of Communication Technology". In Proceedings of the 37th Annual Hawaii International Conference on System Sciences (2004). http://dx.doi.org/10.1109/hicss.2004.1265477

[9] Jeremy Roschelle and Stephanie D. Teasley. The Construction of Shared Knowledge in Collaborative Problem Solving. In C. O'Malley, editor, Computersupported Collaborative Learning, pages 69-97, Berlin, 1995. Springer-Verlag. http://dx.doi.org/10.1007/978-3-642-85098-1

[10] Pierre Dillenbourg. What Do You Mean by Collaborative Learning? In Pierre Dillenbourg, editor, Collaborative-learning: Cognitive and Computational Approaches, pages 1-19. Elsevier, Oxford, 1999.

[11] V. Wendel, , S. Göbel, R. Steinmetz, "Game Mastering in Collaborative Multiplayer Serious Games". E-Learning and Games for Training, Education, Health and Sports - Springer LNCS, Vol. 7516, p. 23-34,(2012). http://dx.doi.org/10.1007/978-3-642-33466-5_3

[12] DW. Johnson, RT. Johnson "Learning together". In: Sharan S, editor. Handbook of cooperative learning methods. Connecticut: Greenwood Press; 1994. 